\title{
ANÁLISE DOS FATORES HUMANOS E CONDIÇÕES DE TRABALHO EM OPERAÇÕES DE IMPLANTAÇÃO FLORESTAL
}

\author{
Eduardo da Silva Lopes ${ }^{1}$, Janaine Vosniak ${ }^{2}$, Nilton César Fiedler ${ }^{3}$, Mário Takao Inoue ${ }^{1}$ \\ ${ }^{1}$ Eng. Florestal, Dr., Depto. de Engenharia Florestal, UNICENTRO, Irati, PR, Brasil - eslopes@pq.cnpq.br; martakino@gmail.com \\ ${ }^{2}$ Eng. Florestal, Mestranda em Ciências Florestais, UNICENTRO, Irati, PR, Brasil - janainevosniak@yahoo.com.br \\ ${ }^{3}$ Eng. Florestal, Dr., Depto. de Engenharia Florestal, UFES, Alegre, ES, Brasil - fiedler@ pq.cnpq.br \\ Recebido para publicação: 10/11/2009 - Aceito para publicação: 30/05/2011
}

\begin{abstract}
Resumo
Este trabalho teve por objetivo analisar os fatores humanos e condições de trabalho nas operações de implantação florestal. A coleta dos dados ocorreu por meio de entrevistas realizadas com 48 trabalhadores florestais das atividades de coveamento, plantio e adubação. Os resultados indicaram que a média de idade dos trabalhadores foi de 31,7 anos, estatura de $170,1 \mathrm{~cm}$ e peso de $74,2 \mathrm{~kg}$; 77,9\% eram de origem rural, 58,9\% eram casados e 77,5\% não concluíram o Ensino Fundamental. Quanto ao tempo de serviço na empresa, a média foi de 30,4 meses e o tempo médio de experiência na função foi de 23,0 meses. Em relação à lateralidade, 58,3\% dos trabalhadores da atividade de coveamento eram destros e $41,7 \%$ eram canhotos, o que podendo influenciar na adaptação dos trabalhadores para a execução da operação. A elevada incidência de dores nas pernas $(40,7 \%)$ e nas costas $(30,3 \%)$ foi afirmada pelos trabalhadores do coveamento como sendo causada pelo elevado peso do equipamento. $\mathrm{O}$ capacete com viseira foi apontado pelos trabalhadores como causa de dores de cabeça e dificuldade de visão, e as luvas como causa de umedecimento das mãos e perda de sensibilidade, situações que podem dificultar o manuseio do perfurador de solo no trabalho.

Palavras-chave: Implantação florestal; fatores humanos; qualidade de vida.
\end{abstract}

\begin{abstract}
Human factors and work conditions analysis in forest planting operations. The aim of this research was to analyze human factors and work conditions in forest planting operations. Data were collected by interviews with 48 workers of hole-digging, planting and fertilizing activities. The results indicated that the workers average age was 31.7 years, height $170.1 \mathrm{~cm}$ and body weight $74.2 \mathrm{Kg}$. $77.9 \%$ were of rural origin, $58.9 \%$ were married and $77.5 \%$ did not reach basic schooling. The average job time in the company was 30.4 months and the average time of activity experience was 23.0 months. Most (58.3\%) of the workers of hole-digging were dexterous and $41.7 \%$ were left-hand, which may influence the adaptation of workers in operation of the equipment. The high incidence of leg $(40.7 \%)$ and back pain (30.3\%) was affirmed by the workers of hole-digging as caused by the high weight of the equipment. The helmet with visor was appointed by workers as cause of headaches and vision difficulty and gloves were identified as cause to wet hands and hardly handling punch land in work.

Keywords: Forest planting; human factors; quality of life.
\end{abstract}

\section{INTRODUÇÃO}

A mão de obra é um componente essencial para o trabalho florestal, principalmente na etapa de implantação, em que, na maioria das vezes, as atividades são executadas por meio de métodos manuais e semimecanizados, envolvendo grande contingente de trabalhadores. Além disso, esses trabalhadores permanecem expostos a condições ambientais desfavoráveis, além de executarem atividades de elevado esforço físico e assumindo posturas inadequadas (FIEDLER, 1988). Tal situação, segundo Iida (1995), pode comprometer a produtividade, causar desconforto e aumentar os riscos de acidentes, além de tornar suscetível o aparecimento de lesões por esforços repetitivos e doenças osteomusculares, provocando danos à saúde dos trabalhadores. 
Segundo Iida (1995), a ergonomia é o conjunto de conhecimentos a respeito do desempenho do ser humano em atividade, a fim de aplicá-los na concepção das tarefas, dos instrumentos, das máquinas e dos sistemas de produção. Para Wisner (1994), a ergonomia pode ainda contribuir para o aumento da satisfação e do bem-estar, propiciando melhor qualidade do trabalho, maior produtividade e menores danos à sua saúde dos trabalhadores.

Dentro de uma análise ergonômica do trabalho, é importante iniciar pelo levantamento dos fatores humanos, conhecendo o perfil dos trabalhadores que interagem com o processo produtivo, bem como das condições de trabalho, envolvendo, dentre outros, aspectos em relação aos hábitos, vícios, treinamento, alimentação, segurança e saúde (VOSNIAK, 2009).

$\mathrm{O}$ estudo dos fatores humanos e das condições de trabalho nas empresas florestais tem por objetivo aperfeiçoar os métodos e as técnicas, assegurando condições mais seguras, confortáveis e saudáveis do ambiente de trabalho. Por isso, o conhecimento dessas condições e a busca por melhorias influenciam diretamente a satisfação dos trabalhadores na empresa, levando ainda ao aumento da produtividade e qualidade do trabalho (GRANDJEAN, 1982; FIEDLER, 1998; MINETTE, 1996; SANT'ANNA, 1998).

Sant'Anna e Malinovski (2002) enfatizam a importância do conhecimento dos fatores humanos e das condições de trabalho, possibilitando dessa forma que a área de trabalho, o seu arranjo, os equipamentos e as ferramentas sejam bem adaptados às capacidades psicofisiológicas, antropométricas e biomecânicas dos trabalhadores.

Para Fiedler (1998), o estudo dos fatores humanos consiste no levantamento do perfil do trabalhador, sendo analisadas variáveis como tempo na empresa, tempo na função, estado civil, número de filhos, idade, escolaridade, origem etc. Já Minette (1996) considera que as principais variáveis para a caracterização do perfil dos trabalhadores são idade, peso, altura, índice de massa corporal, tempo de trabalho na empresa, salário, queixas de lombalgias, estado civil, escolaridade, origem, turno de trabalho etc.

Além disso, o estudo do perfil dos trabalhadores é importante para auxílio na tomada de decisões para a implantação de novas técnicas de treinamento, melhoria das condições de trabalho e satisfação dos trabalhadores, permitindo ainda evitar mudanças constantes de função na empresa (LOPES, 1996).

Por outro lado, as condições de trabalho na empresa são fatores que influenciam diretamente a produtividade dos trabalhadores e a manutenção do sistema ser humano/máquina em funcionamento. Para Iida (1995), é importante que a empresa tenha conhecimento das condições de trabalho, de suas consequências e da satisfação dos trabalhadores, a fim de estabelecer critérios para a aquisição de mão de obra e equipamentos, proporcionar melhor relacionamento entre trabalhadores, administrar e estabelecer mudanças visando a implementação de técnicas de segurança.

Portanto, diante da importância das atividades de implantação florestal, do grande contingente de trabalhadores envolvidos e da existência de poucos trabalhos a respeito desse assunto, objetivou-se com esta pesquisa realizar uma análise dos fatores humanos e das condições de trabalho nas atividades de implantação florestal, visando a obtenção de informações que poderão subsidiar os gestores florestais na melhoria das condições de conforto, segurança e saúde dos trabalhadores.

\section{MATERIAL E MÉTODOS}

Esta pesquisa foi realizada a partir de dados coletados em áreas de implantação de Pinus spp. e Eucalyptus spp. de uma empresa que atua na prestação de serviços florestais, localizada na região do Norte Pioneiro do Estado do Paraná.

As áreas florestais estão localizadas em terrenos com relevo classificado em forte ondulado com declividade entre 20 e 45\%. O clima da região é classificado como Cfa (subtropical úmido mesotérmico), com temperatura média anual de $21^{\circ} \mathrm{C}$ e precipitação média anual entre 1.200 e $1.400 \mathrm{~mm}$ (IBGE, 2008).

A população pesquisada foi composta por uma amostra de 48 trabalhadores florestais, selecionados aleatoriamente e que atuavam nas atividades de coveamento, plantio e adubação. Foram estudados 12 trabalhadores do coveamento, 25 do plantio e 11 da adubação, contemplando $35,1 \%$ da população total de trabalhadores da empresa.

A atividade de coveamento consistia na abertura das covas para o plantio, executada pelo método semimecanizado, com o uso de um perfurador de solo, motor 2 tempos, potência de $1,3 \mathrm{~kW}$ e peso total 
do equipamento abastecido de $10,25 \mathrm{~kg}$. Já a atividade de plantio consistia na inserção das mudas no solo, executada pelo método manual, com o uso de uma plantadeira conectada a uma bomba costal com hidrogel, com peso total de $24,15 \mathrm{~kg}$. Por fim, a adubação consistia na aplicação de adubo, executada também pelo método manual, com uso de uma adubadeira tipo "matraca", ligada ao recipiente de adubo acondicionado nas costas do trabalhador, sendo o peso total do conjunto de $20,7 \mathrm{~kg}$.

$\mathrm{O}$ estudo dos fatores humanos e das condições de trabalho foi realizado durante o mês de abril de 2008. Inicialmente, os trabalhadores receberam esclarecimentos sobre a metodologia e objetivo da pesquisa, por meio da leitura e assinatura do Termo de Consentimento Livre e Esclarecido (TCLE), em atendimento à Resolução no 196/96 da CONEP (Comissão Nacional de Ética em Pesquisa) do Ministério da Saúde.

O levantamento dos fatores humanos e das condições de trabalho foi realizado por meio de questionários individuais aplicados aos trabalhadores na forma de entrevistas no próprio local de trabalho. Foi utilizado um questionário desenvolvido por Fiedler et al. (2002) e adaptado pelos autores, que abordou dados sobre o perfil dos trabalhadores (idade, peso, estatura, escolaridade, origem, estado civil, número de filhos, moradia, experiência na função, vícios e hábitos etc.). Foram ainda levantadas informações em relação às condições de trabalho, contemplando as condições gerais do trabalho, saúde, alimentação, segurança e treinamento.

\section{RESULTADOS E DISCUSSÃO}

\section{Fatores humanos}

Os resultados médios referentes aos fatores humanos dos trabalhadores que atuavam nas atividades de coveamento, plantio e adubação na empresa florestal estudada são apresentados na tabela 1.

Tabela 1. Fatores humanos relacionados aos trabalhadores nas atividades estudadas.

Table 1. Human factors related to workers in the activities studied.

\begin{tabular}{lcccc}
\hline \multirow{2}{*}{ Características analisadas } & \multicolumn{3}{c}{ Valores médios } \\
\cline { 2 - 5 } & Coveamento & Plantio & Adubação & Média \\
\hline Idade (anos) & 32,5 & 32,8 & 29,7 & 31,7 \\
Estatura (cm) & 171,4 & 169,5 & 169,4 & 170,1 \\
Peso (kg) & 78,3 & 72,8 & 71,5 & 74,2 \\
Estado civil (\% de casados) & 58,3 & 64,0 & 54,5 & 58,9 \\
Número de filhos (n) & 1,2 & 1,7 & 1,2 & 1,4 \\
Possuidores de casa própria (\%) & 58,3 & 88,0 & 54,5 & 66,9 \\
Escolaridade (\% Ensino Fundamental Incompleto) & 91,7 & 61,0 & 79,6 & 77,5 \\
Origem Rural (\%) & 66,7 & 76,0 & 90,9 & 77,9 \\
Destreza manual (destros) & 58,3 & 92,0 & 81,8 & 77,4 \\
Tempo de serviço na empresa (meses) & 33,4 & 36,8 & 17,9 & 29,4 \\
Tempo na função (meses) & 19,6 & 30,2 & 14,8 & 21,5 \\
Jornada de trabalho (horas) & 8,0 & 8,0 & 8,0 & 8,0 \\
Distância da residência no período pesquisado $(\mathrm{km})$ & 96,4 & 112,1 & 101,3 & 103,3 \\
\hline
\end{tabular}

A média de idade dos trabalhadores nas atividades de coveamento, plantio e adubação foi de 31,7 anos, estando abaixo do valor encontrado por Ferreira (2006) para trabalhadores de implantação florestal em regiões montanhosas de Minas Gerais (34,5 anos).

A estatura e o peso médio dos trabalhadores no coveamento foram de $171,4 \mathrm{~cm}$ e $78,3 \mathrm{~kg}$, no plantio de $169,5 \mathrm{~cm}$ e $72,8 \mathrm{~kg}$ e na adubação de $169,4 \mathrm{~cm}$ e $71,5 \mathrm{~kg}$, respectivamente. Silveira (2006) obteve para trabalhadores da implantação florestal valores médios de estatura de $1,70 \mathrm{~cm}$ e peso de $68,8 \mathrm{~kg}$.

A maioria dos trabalhadores eram casada $(58,9 \%)$, seguidos pelos solteiros $(15,2 \%)$ e divorciados $(6,5 \%)$. O número médio de filhos foi de 1,4, valor inferior ao encontrado por Minette (1996), Fiedler (1998), Alves (2001) e Silveira (2006), de 2,8; 3,0; 3,2 e 2,0 filhos, respectivamente, em estudos com trabalhadores florestais. O baixo número de filhos foi justificado pelos entrevistados como sendo uma consequência de questões financeiras que limitam a manutenção de uma família com muitos 
membros. Tal resultado evidencia que o fator financeiro é limitador e contribui para o menor número de filhos dos trabalhadores florestais, devendo ainda se ressaltar a tendência nacional de redução da população evidenciada pelo IBGE.

Em relação à escolaridade, em média $77,5 \%$ dos trabalhadores possuíam apenas o Ensino Fundamental incompleto, podendo isso estar correlacionado com a origem rural da maioria dos trabalhadores, que interrompeu os seus estudos pela necessidade de ingressar no mercado de trabalho. Todos os entrevistados declararam ter interesse em concluir os seus estudos com o objetivo de obter melhores oportunidades de trabalho.

A figura 1 mostra o nível de escolaridade dos trabalhadores nas atividades estudadas, destacando-se o fato de não terem sido encontrados trabalhadores analfabetos, fato bastante positivo, que pode contribuir com as empresas na realização de treinamentos. É importante ainda destacar que 91,7\% dos entrevistados do coveamento possuíam o Ensino Fundamental incompleto e apenas 8,3\% possuíam o Ensino Médio completo. No plantio e na adubação, o nível de escolaridade dos trabalhadores estava mais bem distribuído em todos os níveis de ensino, devendo-se ressaltar o baixo índice de trabalhadores com Ensino Médio completo.

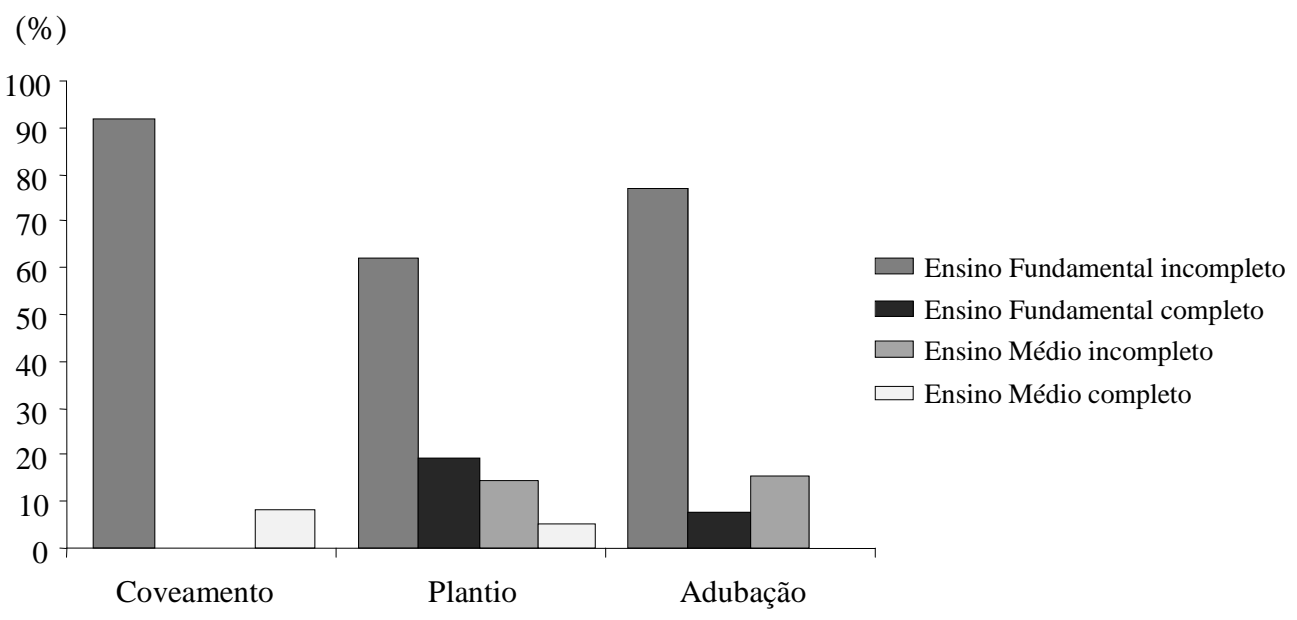

Figura 1. Escolaridade dos trabalhadores nas atividades estudadas.

Figure 1. Education of workers in the activities studied.

Os resultados sobre a origem dos trabalhadores evidenciaram que a maioria dos entrevistados (77,9\%) era de origem rural, valor inferior ao encontrado por Alves (2001), que foi de 86,5\%, e superior ao encontrado por Sant'Anna e Malinovski (2002), com 75,9\%, nas atividades de viveiro e colheita florestal, respectivamente, indicando que a região de atuação da empresa possuía disponibilidade de mão de obra para atividades florestais.

Nas atividades de coveamento, plantio e adubação, verificou-se, respectivamente, que 58,3, 92,0 e $81,8 \%$ dos trabalhadores eram destros. Tal resultado é importante para subsidiar programas de treinamento e o desenvolvimento de ferramentas adaptadas às necessidades de cada trabalhador. É importante ainda destacar o elevado número de trabalhadores canhotos no coveamento $(41,7 \%)$, devendo a empresa atentar para o treinamento desses trabalhadores quanto à adaptação e manuseio dos equipamentos.

Em relação ao tempo de serviço na empresa e na função, verificou-se que a média foi de 30,4 e 23,0 meses, respectivamente. O baixo tempo de serviço na empresa e na função está relacionado ao fato de a empresa estar atuando há pouco tempo no setor de prestação de serviços florestais.

A jornada diária média de trabalho na empresa foi de oito horas, de segunda à sexta-feira, e eventualmente, quando necessário, aos sábados, com pagamento de horas extras aos trabalhadores. O tempo de transporte da sede da empresa ao local de trabalho era variável, dependendo da localização das fazendas, podendo chegar a quatro horas entre as viagens de ida e volta. É importante destacar que a 
empresa pagava aos trabalhadores o tempo consumido no transporte, denominado "hora itinere", valor estabelecido pelo sindicato da categoria em convenção coletiva.

Quando os trabalhadores foram questionados se gostariam de alterar o seu horário de trabalho, $80 \%$ responderam negativamente, estando satisfeitos com o horário de trabalho atual. Entretanto, a maior reclamação referiu-se à demora no retorno do trabalho, ocasionado pelo longo tempo consumido com o transporte, devido à maior distância em determinadas épocas do ano. Uma solução para essa situação seria a disponibilidade de alojamentos em locais próximos às frentes de trabalho, diminuindo o tempo de viagem e os desgastes físicos. Porém, quando indagados, todos os trabalhadores foram unânimes em afirmar que preferem o longo trajeto a permanecer alojados longe da família durante a semana. Além disso, é importante destacar que essa postura faz parte da política de responsabilidade social da empresa em não separar o trabalhador de sua família.

\section{Condições de trabalho}

De acordo com 47,8\% dos trabalhadores entrevistados, não existe diferença significativa na produtividade entre os dias da semana. Quando questionados sobre o dia de menor produtividade, 45,5\% dos entrevistados afirmaram ser a sexta-feira, devido ao cansaço acumulado ao longo da semana e a expectativa da chegada do final de semana. De acordo com Lopes (2007), a identificação do dia da semana de menor produtividade é importante, pois, havendo necessidade de paradas no trabalho para realização de pagamentos, cursos ou treinamentos, tais eventos poderiam ser realizados nesses dias.

Quando questionados se haviam atuado em outras atividades, mesmo sem carteira assinada, antes de ingressarem na empresa, a maioria $(72,6 \%)$ dos trabalhadores respondeu afirmativamente. Dentre as atividades exercidas, destacam-se a indústria madeireira $(36,8 \%)$, o corte de cana $(21,1 \%)$, a construção civil $(18,4 \%)$ e a agricultura $(15,8 \%)$. Tal resultado mostra que o trabalho nas atividades de implantação florestal foi a primeira oportunidade de emprego com carteira assinada para a maioria dos entrevistados, evidenciando a importância da empresa como fonte empregadora para a região na época de realização da pesquisa. Além disso, devido ao fato de a maioria ser originada de atividades ligadas ao meio rural, tal situação poderá favorecer a adaptação dos trabalhadores na execução do trabalho florestal.

Ao serem perguntados sobre o ritmo de trabalho, todos os entrevistados responderam que era controlado por eles mesmos, e as pausas eram estabelecidas de maneira espontânea. Os trabalhadores afirmaram que aproveitavam os momentos de abastecimento dos equipamentos, além de algumas interrupções pessoais, para fazer pausas de repouso. É importante ressaltar a importância no estabelecimento de pausas de menor duração e distribuídas ao longo da jornada de trabalho, devendo ser programadas pela empresa.

Em relação à frequência no trabalho, $71,7 \%$ dos entrevistados declararam que somente faltam ao trabalho quando necessário, sendo doença da própria pessoa ou de um membro da família, perda de horário e compromissos pessoais apontados como os principais motivos. É importante destacar que o motivo da perda de horário pode estar relacionado com o cansaço dos trabalhadores, ocasionado pelo elevado tempo consumido com o transporte entre a sede e as frentes de trabalho em determinadas épocas do ano.

\section{Costumes e vícios}

Com relação aos costumes e vícios, os resultados mostraram que o número de fumantes foi de $21,7 \%$, sendo menor do que os valores encontrados em trabalhadores florestais por Fiedler (1998), de $37,8 \%$, Ferreira (2006), de 50,0\%, e Silveira (2006), de 30,4\%. O maior índice de fumantes encontrado foi no coveamento, com $25,0 \%$, seguido pelo plantio, com $23,8 \%$, e adubação, com $15,5 \%$, com média de 8,8 cigarros consumidos por dia.

Sobre a ingestão de bebidas alcoólicas, $60,9 \%$ dos entrevistados informaram que consomem algum tipo de bebida alcoólica, entretanto somente em ocasiões especiais e eventualmente nos finais de semana.

A respeito do consumo de café, $100 \%$ dos entrevistados informaram trazer de casa, sendo acondicionado em garrafas térmicas. $\mathrm{O}$ consumo médio diário de café pelos trabalhadores do coveamento foi de $450 \mathrm{ml}$, no plantio de $657,1 \mathrm{ml}$ e na adubação de $480,8 \mathrm{ml}$, estando o percentual de consumidor acima do encontrado por Silveira (2006), com 51,5\% para trabalhadores florestais. Tal informação pode 
ser importante em estudos com a finalidade de verificar a perda de sono dos trabalhadores, que em alguns casos pode estar correlacionado com o elevado consumo de café.

Em relação às horas de sono, os entrevistados informaram que, em média, dormiam 6,5 horas diárias, sendo o período considerado suficiente para $71,1 \%$ dos entrevistados. No coveamento, apenas $58,3 \%$ dos trabalhadores consideravam o período de sono suficiente.

\section{Consumo de água e alimentação}

A média de água ingerida pelos trabalhadores durante a jornada de trabalho foi de 3,2 litros, sendo que as garrafas térmicas eram fornecidas pela empresa e a água originada de suas residências. A atividade que apresentou maior consumo de água foi o coveamento, com 3,4 litros, seguido da adubação, com 3,2 litros, e do plantio, com 2,8 litros. O maior consumo no coveamento pode estar relacionado ao maior desgaste físico da atividade e por possível inalação de gases da combustão, conforme relato dos próprios trabalhadores.

Entre os entrevistados, 93,5\% faziam as três principais refeições diárias (café da manhã, almoço e jantar), 95,7\% tomavam café da manhã em casa ou faziam um lanche antes de iniciar suas atividades, $100 \%$ almoçavam, 91,3\% tomavam um lanche à tarde antes da viagem de retorno, 97,8\% jantavam e $8,7 \%$ faziam um lanche antes de dormir.

A empresa fornecia aos trabalhadores um lanche para acompanhar o café trazido de suas residências, enquanto o almoço era preparado no restaurante da empresa. O cardápio era elaborado por nutricionista da empresa, de acordo com as normas do PAT (Programa de Alimentação do Trabalhador), obedecendo aos critérios técnicos estabelecidos pelo Ministério da Saúde em relação à média de calorias necessárias para as atividades florestais.

O cardápio era variável, composto por feijão, arroz ou massa, carne vermelha ou branca, guarnição como farofa ou legumes cozidos, salada e refrigerante ou suco, além de um doce ou fruta como sobremesa. Os alimentos cozidos eram acondicionados em panelões lacrados com um dispositivo de plástico e aquecidos em banho-maria na hora do almoço no próprio local de trabalho, ou, dependendo da distância, em recipientes do tipo "marmitex". É importante ressaltar que o uso dos panelões é necessário nos casos de longa distância entre a sede da empresa e as frentes de trabalho, pois os alimentos acondicionados em "marmitex" perdem o calor mais rapidamente, comprometendo a qualidade da refeição.

Os trabalhadores faziam as refeições em locais adequados nas frentes de trabalho, denominadas "áreas de vivência", conforme determina a NR-31 (Segurança e Saúde no Trabalho na Agricultura, Pecuária, Silvicultura, Exploração Florestal e Aquicultura). Essas áreas eram compostas por barracas de lona com banquetas dobráveis, lixeira com separação de resíduos e instalações sanitárias com vaso sanitário, papel higiênico, lavatório com água, detergente e toalhas descartáveis.

Entretanto, observou-se que a maioria dos trabalhadores não fazia uso regular das instalações sanitárias, por falta de hábito e por constrangimento em relação aos colegas. É importante enfatizar que muitos afirmaram que não usavam as instalações sanitárias por considerarem o espaço interno da cabine reduzido. Sendo assim, apesar das instalações sanitárias utilizadas pela empresa estarem de acordo com a NR-31, os resultados mostram a necessidade da revisão dessa norma, por meio do dimensionamento das instalações sanitárias, de forma a atender ao maior conforto dos trabalhos, pois a norma estabelece apenas a proporção de número de vasos sanitários por quantidade de usuários.

\section{Saúde}

Em relação à saúde, a maioria dos entrevistados $(80,4 \%)$ afirmou não ter tido problemas de saúde nos últimos tempos, devendo-se destacar a preocupação com a saúde dos trabalhadores por parte da empresa que, em parceria com instituições de saúde, fornece medicamentos fitoterápicos.

Em relação às partes do corpo onde sentiam mais dores, os trabalhadores afirmaram ser as pernas, costas, braços, ombros, mãos, músculos e região dos rins, causadas pela declividade do terreno, os constantes e longos deslocamentos no interior do talhão durante o trabalho e a postura inadequada adotada em algumas etapas do trabalho. As figuras 2, 3 e 4 mostram as partes do corpo em que os entrevistados sentiam mais dores nas atividades de coveamento, plantio e adubação.

Os trabalhadores informaram que as dores nos braços, ombros e mãos podem ser causadas pelo peso e desconforto dos equipamentos. Tal resultado mostra a importância de se realizarem, em parceria 
com fabricantes, pesquisas para o desenvolvimento de equipamentos e acessórios mais leves e adaptados às condições antropométricas dos usuários, bem como estabelecer o rodízio de funções e fiscalizar quanto à realização da ginástica laboral de pausas, pois essa última exigência não estava sendo cumprida pelos trabalhadores, sendo em seguida solucionada pela direção da empresa.

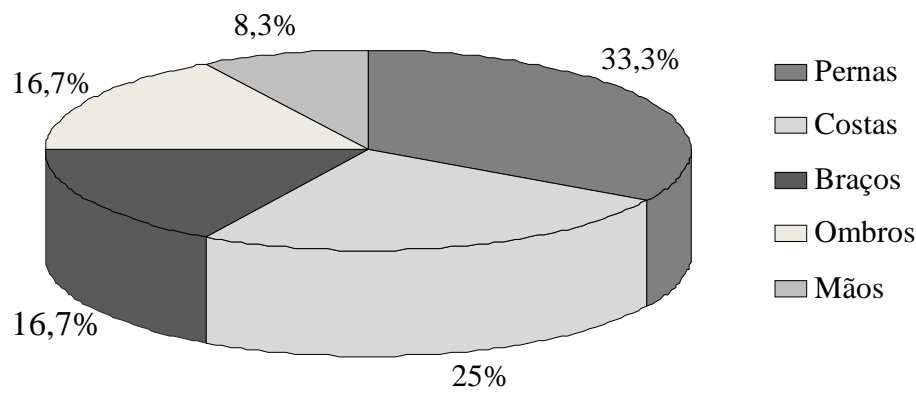

Figura 2. Partes do corpo dos trabalhadores do coveamento com indicação de dores.

Figure 2. Body parts of workers in hole-diggings with indication of pain.

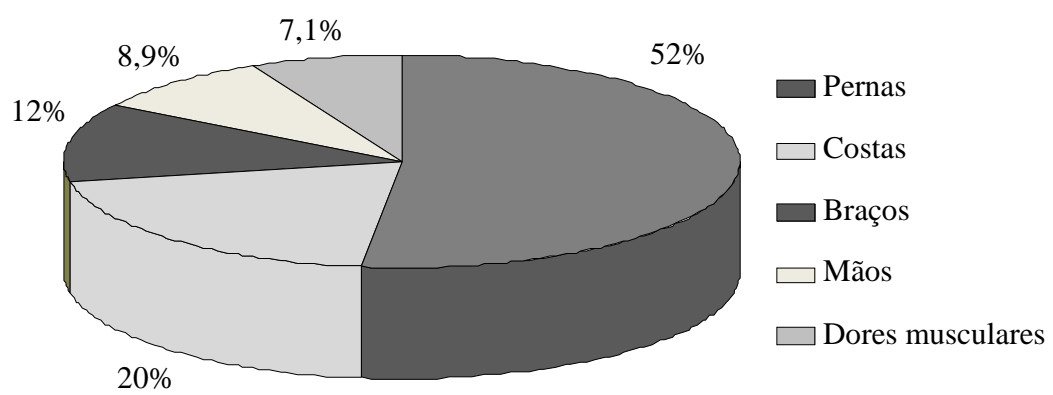

Figura 3. Partes do corpo dos trabalhadores do plantio com indicação de dores.

Figure 3. Body parts of workers in planting with indication of pain.

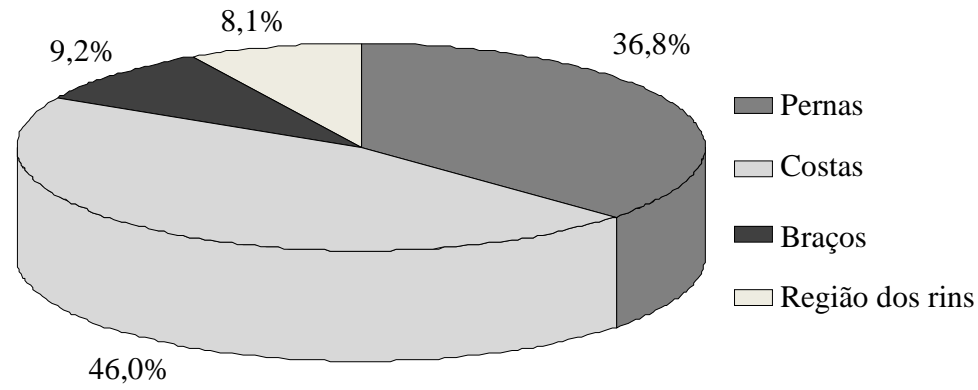

Figura 4. Partes do corpo dos trabalhadores da adubação com indicação de dores.

Figure 4. Body parts of workers in fertilization with indication of pain. 
Entre os entrevistados, $17,4 \%$ ainda informaram sentir dores nos olhos, ouvidos e problemas respiratórios, causados pela característica do trabalho florestal e, possivelmente, pelo excesso de iluminação, ruído e irritação à poeira, sendo esse último de ocorrência em determinados locais e época do ano.

Sobre os fatores físicos do ambiente de trabalho (condições climáticas, ruído, vibração e poeira), os entrevistados do coveamento, plantio e adubação, em 87,5, 76,2 e 60,0\% das opiniões, respectivamente, responderam ser o calor a condição mais inadequada e que influencia a execução do trabalho, pois ele era realizado em campo aberto. Entre os fatores que mais causaram problemas estavam a vibração do perfurador de solo $(50,0 \%)$, o ruído $(25,0 \%)$ e os odores de combustíveis $(16,7 \%)$. Na adubação e plantio, 38,5 e 23,8\% dos entrevistados, respectivamente, reclamaram da poeira, que causava irritações nas narinas e pulmões, renites e gripes frequentes, principalmente quando o trabalho era realizado próximo às estradas vicinais, em épocas de colheita agrícola, com tráfego intenso de caminhões e tratores.

\section{Segurança no trabalho}

Em relação à segurança no trabalho, 17,4\% dos entrevistados afirmaram já terem sofrido algum acidente de trabalho, sendo as pernas e as mãos as partes do corpo mais atingidas. Os motivos dos acidentes foram para 54,6\% o descuido na execução do trabalho, seguido pelo cansaço para $33,3 \%$ dos entrevistados.

A empresa fornecia todos os equipamentos de proteção individual (EPI's) necessários ao trabalho, com as reposições sendo realizadas semanalmente pelos técnicos de segurança do trabalho. Todos os entrevistados informaram ser importante o uso dos EPI's, sendo os mais importantes a perneira $(45,8 \%)$, a bota (32,7\%), o capacete e o protetor auricular (16,9\%) e o boné árabe $(4,6 \%)$.

Em relação ao incômodo causado pelo uso dos EPI's, 26,1\% dos entrevistados apontaram o capacete com viseira como o mais incômodo, causando dores de cabeça e dificuldade na visão. Em seguida, a luva $(15,2 \%)$ foi apontada pelos trabalhadores como causadora de umedecimento das mãos e perda de sensibilidade tátil, situações que podem dificultar o manuseio do equipamento na execução do trabalho. Tal resultado é importante para que os fabricantes possam ajustar e desenvolver EPI's capazes de solucionar os problemas encontrados na pesquisa, principalmente em relação ao capacete e às luvas.

Sobre a segurança das máquinas e ferramentas, a maioria respondeu serem seguras e fáceis de operar. Entretanto, no coveamento, $25,0 \%$ dos trabalhadores informaram ter dificuldades na operação do perfurador de solo e $54,3 \%$ que a máquina não oferecia condições de segurança, sendo o "rebote" da máquina o principal motivo.

\section{Treinamento}

Com relação ao treinamento, $100,0 \%$ dos trabalhadores do coveamento receberam treinamento, seguido pelo plantio, com $85,7 \%$, e adubação, com $61,1 \%$. A tabela 2 mostra os aspectos relativos ao treinamento dos trabalhadores.

Tabela 2. Percepção dos trabalhadores em relação ao treinamento.

Table 2. Perception of workers in relation to training.

\begin{tabular}{lcccc}
\hline Percepção & $\begin{array}{c}\text { Coveamento } \\
(\boldsymbol{\%})\end{array}$ & $\begin{array}{c}\text { Plantio } \\
(\mathbf{\%})\end{array}$ & $\begin{array}{c}\text { Adubação } \\
(\mathbf{\%})\end{array}$ & $\begin{array}{c}\text { Média geral } \\
(\mathbf{\%})\end{array}$ \\
\hline Receberam treinamento para a função & 100,0 & 85,7 & 61,1 & 82,3 \\
Considerou o tempo de treinamento suficiente & 66,7 & 90,5 & 76,9 & 78,0 \\
Gostaria de receber novos treinamentos & 94,8 & 61,9 & 69,2 & 77,0 \\
Recebeu treinamento sobre higiene e primeiros & 41,7 & 33,3 & 61,5 & 45,5 \\
socorros & 83,3 & 66,7 & 51,3 & 67,1 \\
Tem conhecimento sobre CIPA, segurança e legislação & & & & \\
\hline
\end{tabular}

Quando questionados se gostariam de receber novos treinamentos para aperfeiçoar algumas técnicas de trabalho, $94,8 \%$ dos entrevistados do coveamento responderam afirmativamente, seguido pelo plantio, com $61,9 \%$, e adubação, com $69,2 \%$. Tal resultado mostra a importância que o treinamento exerce sobre o trabalhador e o interesse destes em evoluir e melhorar na execução de suas funções, 
principalmente no coveamento, que é uma atividade causadora de maior desgaste físico e risco de acidentes.

Ao serem perguntados sobre a importância da oferta de treinamentos em relação às práticas de higiene no trabalho e primeiros socorros, $41,7 \%$ dos trabalhadores do coveamento, $33,3 \%$ do plantio e $61,5 \%$ da adubação responderam positivamente. Apesar de a maioria ter considerado desnecessária a oferta desses treinamentos, fica evidente a importância de maiores esclarecimentos por meio da implantação desses treinamentos, que contribuirá com a maior segurança, saúde e qualidade de vida dos trabalhadores.

\section{CONCLUSÕES}

Com base nos resultados obtidos, as conclusões desta pesquisa foram:

- Os trabalhadores que atuavam nas atividades de implantação florestal na região onde foi conduzida a pesquisa foram caracterizados por serem de origem rural, casados, com baixo nível de escolaridade, com elevado percentual de indivíduos treinados para as funções e possuidores de pouca experiência e tempo de serviço na função.

- As pausas no trabalho foram realizadas pelos próprios trabalhadores e de forma espontânea, evidenciando a importância da empresa em estabelecer pausas programadas de menor duração e distribuídas ao longo da jornada de trabalho.

- O coveamento foi a atividade apontada pelos trabalhadores como sendo a mais perigosa e de maior desgaste físico, evidenciando a necessidade da ampliação dos treinamentos e a realização de novos estudos ergonômicos nessa atividade.

- O capacete com viseira e as luvas foram apontados pelos trabalhadores como sendo os maiores causadores de incômodo no trabalho, mostrando a necessidade de parcerias com os fabricantes para a melhoria dos equipamentos em termos de maior conforto e segurança dos trabalhadores.

- O fato de os trabalhadores não fazerem uso regular das instalações sanitárias por falta de hábito e por considerarem o espaço interno reduzido mostra que a Norma Regulamentadora necessita ser revista, com o estabelecimento de medidas mínimas necessárias para o maior conforto dos usuários.

\section{REFERÊNCIAS}

ALVES, J. U. Avaliação ergonômica das atividades de propagação vegetativa de Eucalyptus spp. em viveiros. 94 f. Dissertação (Mestrado em Ciência Florestal) - Universidade Federal de Viçosa, Viçosa, 2001.

CONAW, P. L. Estatística. São Paulo: Edgard Blucher, 1977. 264 p.

FERREIRA. P. C. Avaliação ergonômica de algumas operações florestais no município de Santa Bárbara, MG. 61 p. Dissertação (Mestrado em Meio Ambiente e Sustentabilidade) - Centro Universitário de Caratinga, UNEC, Caratinga, MG, 2006.

FIEDLER, N. C. Análise de posturas e esforços despendidos em operação de colheita florestal no litoral do estado da Bahia. 103 p. Tese (Doutorado em Ciência Florestal) - Universidade Federal de Viçosa, Viçosa, MG, 1998.

GRANDJEAN, E. Fitting the task to the man: an ergonomic approach. London: Taylor \& Francis, 1982. $379 \mathrm{p}$.

INSTITUTO BRASILEIRO DE GEOGRAFIA E ESTATÍSTICA (IBGE). Disponível em: <http://www.ibge.gov.br>. Acesso em: 20/04/2008.

IIDA, I. Ergonomia: projeto e produção. 6. ed. São Paulo: Edgard Blucher, 1995.

LOPES, E. S. Diagnóstico do treinamento de operadores de máquinas na colheita florestal. $137 \mathrm{f}$. Dissertação (Mestrado em Ciências Florestais) - Universidade Federal de Viçosa, Viçosa, 1996.

LOPES, E. S.; DOMINGOS, D. M. Estudo dos fatores humanos e condições de trabalho na colheita de 
erva-mate (Ilex paraguariensis St.-Hill.). Ciências Exatas e Naturais, Guarapuava, v. 9, n. 1, p. 143 153, 2007.

MINETTE, L. J. Análise de fatores operacionais e ergonômicos na operação de corte florestal com motosserra. 211 f. Tese (Doutorado em Ciência Florestal) - Universidade Federal de Viçosa, Viçosa, 1996.

SANT'ANNA, C. M. Análise de fatores ergonômicos no corte de eucalipto com motosserra em região montanhosa. 163 p. Tese (Doutorado em Engenharia Florestal) - Universidade Federal do Paraná, Curitiba, 1998

SANT’ANNA, C. M.; MALINOVSKI J. R. Análise de fatores humanos e condições de trabalho de operadores de motosserra de Minas Gerais. Cerne, v. 8, n. 1, p. 115 - 121, 2002.

SILVA, K. R.; SOUZA, A. P.; MINETTI, L. J. Avaliação do perfil de trabalhadores e das condições de trabalho em marcenarias no município de Viçosa, MG. Árvore, Viçosa, v. 26, n. 6, 2002.

SILVEIRA, F. S. A. Avaliação ergonômica das atividades de coveamento manual, coveamento semimecanizado, plantio manual e aplicação de corretivo do solo na implantação florestal de eucalipto. 66 f. Dissertação (Mestrado em Meio Ambiente e Sustentabilidade) - Centro Universitário de Caratinga, UNEC, Caratinga, MG, 2006.

VOSNIAK, J. Avaliação ergonômica das atividades de implantação florestal no norte do Paraná. 100 f. Dissertação (Mestrado em Ciências Florestais) - Universidade Estadual do CentroOeste/UNICENTRO, Campus de Irati, PR, 2009.

WISNER, A. A inteligência do trabalho: textos selecionados de ergonomia. Tradução: Roberto Leal Ferreira. São Paulo: FUNDACENTRO, 1994. 191 p. 